\title{
Clinical Outcomes of a 14-Day In-Hospital Stay Program in Patients Undergoing Head and Neck Cancer Surgery With Free Flap Reconstruction Under the National Health Insurance System
}

\author{
Ji-Eun Choi $($ b $\cdot$ Heejung Kim · Sung Yong Choi $\cdot$ Jongwon Park $\cdot$ Man Ki Chung $\cdot$ Chung-Hwan Baek $\cdot$ Han-Sin Jeong (i) \\ Department of Otorhinolaryngology-Head and Neck Surgery, Samsung Medical Center, Sungkyunkwan University School of Medicine,
}

Seoul, Korea

Objectives. Length of in-hospital stay (LOS) is often regarded as a surrogate marker of efficiency in medical care. A shorter stay can redistribute medical resources to more patients if patient outcomes would not be worsened. However, the adequate LOS remains largely understudied for a complex head and neck cancer (HNC) surgery and free flap reconstruction.

Methods. Active management of LOS (14-day LOS program) included detailed preoperative surgical planning, intensive wound care, postoperative early ambulation and positive psychological encouragement. It was applied to 43 patients undergoing HNC surgery and free flap reconstruction. Outcomes such as noninferior oncological results, rates of timely adjuvant treatments and complications were compared with those of 125 patients without active management of LOS. In addition, the medical costs of shortened LOS were compared with those of the control group. Cases undergoing HNC surgery as a salvage treatment were excluded from both groups for analyses.

Results. Active management of LOS resulted in less in-hospital period compared to the control group (15.0 vs. 21.0 days, $P=0.001$ ), and reduced medical costs significantly. Incidence of postoperative complications was comparable between the two groups. Oncological outcomes did not differ significantly according to LOS. In all patients in both groups, initial high T status (T3-4) and occurrence of postoperative complications were independent risk factors for long LOS (>30 days).

Conclusion. In patients undergoing HNC surgery with free flap reconstruction as an initial treatment, a 14-day LOS could be safe in terms of comparable oncological outcomes and postoperative complications. To achieve this goal safely, careful management for T3-4 tumors and prevention of postoperative complications seem to be necessary.

Keywords. Head and Neck Neoplasms; Reconstructive Surgical Procedures; Length of Stay; Outcomes

- Received August 22, 2018

Revised December 6, 2018

Accepted December 31, 2018

- Corresponding author: Han-Sin Jeong

Department of Otorhinolaryngology-Head and Neck Surgery, Samsung

Medical Center, Sungkyunkwan University School of Medicine,

81 Irwon-ro, Gangnam-gu, Seoul 06351, Korea

Tel: +82-2-3410-3579, Fax: +82-2-3410-6987

E-mail: hansin.jeong@samsung.com

\section{INTRODUCTION}

For complex head and neck cancer (HNC) surgery, on-site reconstruction after cancer ablation seems to be mandatory for anatomic and functional recovery of HNC patients. Previously, it has been reported that free flap reconstruction for head and neck defect is cost-inefficient, due to long operative time and long length of in-hospital stay (LOS) with high complication

Copyright $\odot 2019$ by Korean Society of Otorhinolaryngology-Head and Neck Surgery.

This is an open-access article distributed under the terms of the Creative Commons Attribution Non-Commercial License (http://creativecommons.org/licenses/by-nc/4.0)

which permits unrestricted non-commercial use, distribution, and reproduction in any medium, provided the original work is properly cited. 
rates [1]. With surgical refinement, technical advancement, and improvement of intensive care, recent studies have shown less complications [2-5], improved cosmesis and function [5,6], shorter LOS $[2,3,5,6]$, and less resource utilization [6] in free flap reconstruction, compared to pedicled flap reconstruction [7].

LOS in free flap reconstruction for head and neck defects differ considerably depending on the type of funding in each country and community healthcare systems available [8]. The average LOS ranges from 8 to 13 days in the United States [9-12] and 8 to 35 days in Europe $[13,14]$. In a report from France, the mean LOS was 32.0 days (range, 11 to 70 days) for reconstructive surgery with fibular free flap, 23.3 days (7 to 50 days) for forearm free flap, and 37.8 days (10 to 101 days) for jejunum free flap [8]. In contrast, the mean LOS in USA was only 7 days with forearm or fibular free flap reconstruction [1].

In South Korea, the National Health Insurance System insures a national population against the costs of healthcare for serious diseases including cancer. Thus, a proper distribution of medical resources is critical for the sound system. Patients tend to stay longer in hospital because of low individual cost and the lack of supportive care outside the hospital in Korea. However, some studies have suggested that LOS is a component of medical resource utilization and a reliable parameter for measuring the consumption of hospital resource $[7,15]$. A shorter LOS can redistribute medical resources to more patients if patient outcomes would not be compromised.

To reduce surgical morbidity and LOS while enhancing recovery, several intervention programs have been developed [16-18]. Results have clearly demonstrated the superiority of these programs in terms of better outcomes and less LOS in orthopedic, abdominal, gynecological, colorectal, and HNC surgeries [16-19]. In line with the concept of enhanced recovery after surgery (ERAS), we tried a 14-day LOS program for patients undergoing HNC surgery and free flap reconstruction. Placing particular emphasis on LOS, the primary objective of this study was to present outcomes of a 14-day LOS program and to identify risk factors for prolonged LOS in patients undergoing HNC surgery and free flap reconstruction.

\section{H I}

- Length of in-hospital stay (LOS) is a surrogate marker of efficiency in medical care.

- As for head and neck cancer surgery with flap reconstruction, a 14-day LOS could be safe.

- T3-4 tumors and postoperative complications were independent risk factors for long LOS.

- Careful management forT3-4 tumors and complications seems to be necessary to shorten LOS.
14-Day LOS program
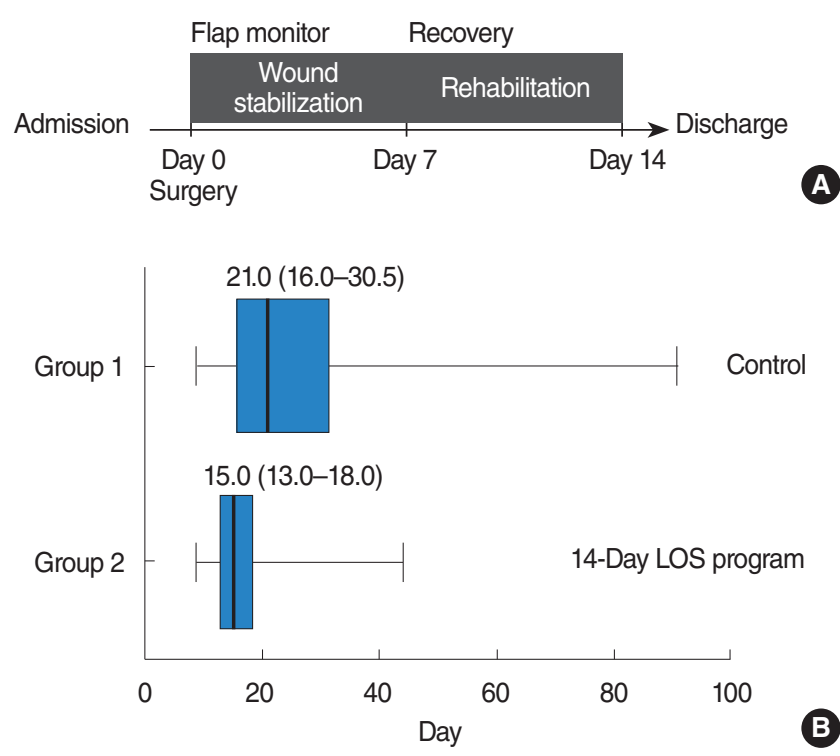

Fig. 1. (A) Schematic illustration showing a 14-day length of in-hospital stay (LOS) program for head and neck cancer patients with ablative surgery and on-site free flap reconstruction. (B) Average LOS duration (day) for groups with and without active management of LOS. Group 1, patients without active management of LOS; Group 2, patients under a 14-day LOS program. Values are presented as median (interquartile range). $P<0.001$.

\section{MATERIALS AND METHODS}

\section{Active management of LOS}

LOS was defined as the number of days between admission and discharge. As a clinical practice, one author (HSJ) started a 14day LOS program for HNC patients with free flap reconstruction from 2014 (Fig. 1A). The program included the following: (1) detailed preoperative surgical planning, (2) meticulous wound care (less secondary healing and early intervention of complication), and (3) early rehabilitation (early ambulation, early extubation and weaning of tracheostomy tubes, swallowing rehabilitation via individualized swallowing therapy, active nutritional support and positive psychological encouragement). Patients were frequently noticed of a 14-day hospital stay preoperatively and at the time when the reconstructed wound was stabilized. Criteria for hospital discharge were: (1) wound healing without a need for professional care, (2) stable spontaneous respiration, (3) per oral diet more than soft blended diet, and (4) tolerable pain or discomfort with oral drugs.

\section{Study and control subjects}

The control group (group 1, $\mathrm{n}=125$ ) consisted of HNC patients with free flap reconstruction without receiving active management of LOS during the same study period (2014-2017). The number of patients enrolled into a 14-day LOS program (group 2) was 43. Patients usually admitted 1 day before surgery. The 
median LOS was 15 days for group 2 and 21 days in group 1 (the control group; $P<0.001$ ) (Fig. 1B). Responsible surgeons had similar experiences for HNC surgery and free flap reconstruction (>10 years). Treatments for patients followed the National Comprehensive Cancer Network guideline.

Some patients with laryngeal or hypopharyngeal cancer were reconstructed with jejunal free flap. These patients were managed postoperatively in the other department of surgery in our institute. Thus, patients with jejunal free flap were excluded from the current analysis. Enrolled patients were cared under the Department of Head and Neck Surgery during all hospital stay. When we compared patients with and without bony reconstruction in addition to soft tissue reconstruction, durations of LOS were not different between two groups according to reconstruction types (Supplementary Table 1). Thus, we included both patients with and without bony reconstruction into analyses. In addition, we excluded HNC patients undergoing salvage surgery $(\mathrm{n}=19)$ after initial (primary) nonsurgical treatments, because the dose, extent, and regimen of previous treatments might significantly affect surgical morbidity and duration of LOS.

\section{Study hypothesis and outcome analyses}

The study hypothesis was that a 14-day LOS program could have similar (noninferior) oncological outcomes without showing increased risk of complications, compared to patients without active management of LOS.

Detailed clinicopathologic data including demographic characteristics, LOS, comorbidity, clinical courses such as oncological outcome, adjuvant therapy and postoperative complication were abstracted from medical records. Surgical complications were defined as any adverse event at the surgical site. They were categorized as transposed flap complications, flap donor site complications, and neck wound problems. Medical complications were also recorded. They were defined as uneventful systemic events distant to surgical sites.

The median follow-up duration for all subjects was 13.5 months with a range of 0.2 to 42.8 months. Particularly for cases without any events (recurrence, residual disease, deaths or second cancer), the minimum duration of follow-up was 24 months. In addition to group comparison, we conducted an analysis of risk factors predicting long LOS ( $>30$ days) using all patients in both groups ( $\mathrm{n}=168$ ), because this time point ( 30 days) could be critical for timely postoperative adjuvant treatment.

\section{Cost analyses}

Between the two groups, total medical costs which patients had paid for their hospital stay were calculated for each patient. In South Korea, all national people are either under national medical insurance or Medicaid system. Because medical costs are different according to medical insurance systems, we separately analyzed the actual medical cost between the two groups depending on medical coverage systems.

\section{Statistical analysis}

Standard statistical analysis was performed using IBM SPSS ver. 20.0 (IBM Corp., Armonk, NY, USA). Variables were compared between the groups using Student $t$-test (or Mann-Whitney test), or chi-square test (or Fisher exact test). LOS was dichotomized into two categories ( $\leq 30$ days, and $>30$ days). A logistic regres-

Table 1. Baseline characteristics of two groups

\begin{tabular}{|c|c|c|c|}
\hline Variable & Group $1(n=125)$ & Group $2(n=43)$ & $P$-value \\
\hline Age (yr) & $6.7 \pm 1.1(23-86)$ & $57.1 \pm 13.2(25-77)$ & 0.694 \\
\hline Sex (male:female) & $83: 42(66.4: 33.6)$ & $34: 9(79.1: 20.9)$ & 0.129 \\
\hline Patient physical status & & & 0.871 \\
\hline ASA 1 & $28(22.8)$ & $11(25.6)$ & \\
\hline ASA 2 & 89 (71.2) & $29(67.4)$ & \\
\hline ASA 3 & $8(6.5)$ & $3(7.0)$ & \\
\hline Primary site & & & 0.116 \\
\hline $\begin{array}{l}\text { Oral cavity \& } \\
\text { oropharynx }\end{array}$ & $91(72.8)$ & $30(69.7)$ & \\
\hline $\begin{array}{l}\text { Larynx \& } \\
\text { hypopharynx }\end{array}$ & $7(5.6)$ & 0 & \\
\hline $\begin{array}{l}\text { Nasal cavity \& } \\
\text { paranasal sinus }\end{array}$ & $16(12.8)$ & $3(7.0)$ & \\
\hline Salivary gland & $2(1.6)$ & 0 & \\
\hline Others & $9(7.2)$ & $10(23.3)$ & \\
\hline \multicolumn{4}{|l|}{ pTNM stage } \\
\hline T status & & & 0.152 \\
\hline T1 & $20(16.0)$ & 7 (16.3) & \\
\hline $\mathrm{T} 2$ & $47(37.6)$ & $17(39.5)$ & \\
\hline T3 & $17(13.6)$ & 7 (16.3) & \\
\hline $\mathrm{T} 4 \mathrm{a}$ & $39(31.2)$ & $8(18.6)$ & \\
\hline$T 4 b$ & $2(1.6)$ & $3(7.0)$ & \\
\hline $\mathrm{T} 4 \mathrm{c}$ & 0 & $1(2.3)$ & \\
\hline $\mathrm{N}$ status & & & 0.410 \\
\hline NO & $70(56.0)$ & $27(62.7)$ & \\
\hline N1 & $13(10.4)$ & $7(16.3)$ & \\
\hline $\mathrm{N} 2 \mathrm{a}$ & $3(2.4)$ & $2(4.7)$ & \\
\hline $\mathrm{N} 2 \mathrm{~b}$ & $30(24)$ & $5(11.6)$ & \\
\hline N2c & $8(6.4)$ & $2(4.7)$ & \\
\hline N3 & $1(0.8)$ & 0 & \\
\hline M status & & & 0.448 \\
\hline MO & 124 (99.2) & $42(97.7)$ & \\
\hline M1 & $1(0.8)$ & $1(2.3)$ & \\
\hline Reconstruction method & & & $0.047^{\mathrm{a})}$ \\
\hline Anterolateral thigh & $69(55.2)$ & $18(41.9)$ & \\
\hline Radial forearm & $34(27.2)$ & $20(46.5)$ & \\
\hline Fibula & $7(5.6)$ & $3(7.0)$ & \\
\hline Scapula & $11(8.8)$ & 0 & \\
\hline Multi-flaps & $1(0.8)$ & 0 & \\
\hline Others & $3(2.4)$ & $2(4.7)$ & \\
\hline
\end{tabular}

Values are presented as median \pm standard deviation (range) or number (\%). No preoperative treatments are in both groups.

Group 1, patients without active management of LOS; Group 2, patients under a 14-day LOS program; ASA, American Society of Anesthesiologists Physical Status Classification; pTNM, pathological TNM; LOS, length of in-hospital stay.

a) Soft tissue alone vs. bony reconstruction, $P=0.675$. 
sion model was used to compare associations between dependent variables. Parameters found to be significant $(P<0.1)$ from univariate analyses were included and analyzed into a multivariate analysis. All statistical tests were two-sided, and $P$-values of less than 0.05 were considered statistically significant. Relative risk, odds ratios, and 95\% confidence intervals (CIs) were calculated to determine the comparative risk of each parameter.

\section{Ethics statement}

This was a retrospective study for patients in both groups. This study protocol was approved by Institutional Review Board (IRB No. 2010-05-090 and 2015-06-132). The patients submitted their written informed consents for the use of their medical information in the HNC registry under a prospective enrollment protocol.

\section{RESULTS}

\section{Outcomes of a 14-day LOS program}

Patients under a 14-day LOS program (group 2, n=43) were compared to those in the control group without receiving active management of hospital stay (group 1, $n=125$ ). Fig. 1B shows difference in LOS between the two groups. Baseline clinicopathological variables between the two groups are summarized in Table 1. Median age, sex, patient physical status did not differ significantly between the two groups. Major subsites of HNC were oral cavity and oropharynx in both groups. No difference in primary sites of tumor, or pathological staging within groups was found. However, squamous cell carcinomas were more fre-

Table 2. Postoperative complications

\begin{tabular}{lccc}
\hline Variable & $\begin{array}{c}\text { Group 1 } \\
(n=125)\end{array}$ & $\begin{array}{c}\text { Group 2 } \\
(n=43)\end{array}$ & $P$-value \\
\hline Surgical complication & $55(44.0)$ & $16(37.2)$ & 0.993 \\
\hline Transposed flap complication & $23(18.4)$ & $8(18.6)$ & \\
Flap fail \& revision & $5(4.0)$ & $2(4.7)$ & \\
Partial necrosis \& congestion & $11(8.8)$ & $4(9.3)$ & \\
Flap dehiscence & $7(5.6)$ & $2(4.7)$ & \\
Flap donor site complication & $6(4.8)$ & $2(4.7)$ & \\
Neck wound problem & $17(13.6)$ & $4(9.3)$ & \\
Fistula & $3(2.4)$ & 0 & \\
Others & $6(4.8)$ & $2(4.6)$ & \\
Medical complication & $13(10.4)$ & $3(6.9)$ & 0.750 \\
Cardiac & $4(3.2)$ & 0 & \\
Respiratory & $2(1.6)$ & $1(2.3)$ & \\
Neurological & $3(2.4)$ & $2(4.6)$ & \\
Psychiatric & $2(1.6)$ & 0 & \\
Vascular & $1(0.8)$ & 0 & \\
Endocrine & $1(0.8)$ & 0 & \\
\hline
\end{tabular}

Values are presented as number (\%).

Group 1, patients without active management of LOS; Group 2, patients under a 14-day LOS program; LOS, length of in-hospital stay. quent in group 1; whereas sarcoma and adenoid cystic carcinomas were more common in group $2(P=0.004)$ (Supplementary Table 2). With regard to reconstruction method, reconstruction with anterolateral thigh was more common in group 1 . However, no statistical difference was found between the two groups, in terms of soft tissue or bony reconstruction.

First, we compared the occurrence of postsurgical complication between the two groups (Table 2). Surgical complications were developed in 55 cases $(44.0 \%)$ in group 1, and 16 cases $(37.2 \%)$ in group $2(P=0.993)$. Medical complication rate was $10.4 \%$ in group 1 and $6.9 \%$ in group $2(P=0.750)$. Therefore, there were no significant differences in overall postsurgical complication rates (surgical or medical) between the two groups.

Group 2 had more adjuvant radiation alone (51.2\%) than group 1 (31.2\%) (Supplementary Table 3). Group 1 patients had more chemo-radiation compared to group 2 (37.6\% vs. $18.6 \%$, $P=0.034)$. The primary reason for higher frequency of adjuvant chemo-radiation in the group 1 was that there were more squamous cell carcinomas in the group $1(87.2 \%)$ compared with those in the group $2(67.4 \%)$. The salivary gland cancers, sarcomas and other type of cancers were more prevalent in the group 2. Postoperative chemo-radiation is a standard adjuvant treatment for high-risk (with adverse features) squamous cell carcinomas in the head and neck. Meanwhile, the postoperative radiation can be a common adjuvant treatment for other pathologies. Radiation dose and chemotherapy regimen did not differ significantly between the two groups.

Long LOS could possibly delay timely postoperative adjuvant treatments. Time interval between surgery and adjuvant therapy did not show significant difference (38.1 days in both groups, $P=0.90$ ). Even in group 1 (without active management of LOS), postoperative adjuvant treatments were not delayed for most patients.

Next, we investigated oncological outcomes for both groups (Table 3). Local recurrence rate was $22.4 \%$ in group 1 and $18.6 \%$ in group $2(P=0.672)$. Regional and distant recurrence did not differ significantly between the two groups. Twelve

Table 3. Oncological outcomes

\begin{tabular}{lcll}
\hline Oncological result & $\begin{array}{c}\text { Group 1 } \\
(n=125)\end{array}$ & $\begin{array}{c}\text { Group 2 } \\
(n=43)\end{array}$ & $P$-value \\
\hline $\begin{array}{l}\text { Recurrence } \\
\text { Local }\end{array}$ & $28(22.4)$ & $8(18.6)$ & 0.672 \\
$\quad$ Regional & $18(14.4)$ & $5(11.6)$ & 0.799 \\
$\quad$ Distant & $16(12.8)$ & $5(11.6)$ & 0.540 \\
Residual disease & $6(4.8)$ & $1(2.3)$ & 0.679 \\
Cancer-related death & $12(9.6)$ & $2(2.7)$ & 0.366 \\
Diagnosis of second cancer & $25(20.0)$ & $8(18.6)$ & 0.518 \\
\hline
\end{tabular}

Values are presented as number (\%). The median follow-up for all subjects is 13.5 months (range, 0.2 to 42.8 months). The minimum duration of follow-up in cases without any events is 24 months.

Group 1, patients without active management of LOS; Group 2, patients under a 14-day LOS program; LOS, length of in-hospital stay. 
$(9.6 \%)$ patient in group 1 and two $(2.7 \%)$ in group 2 had cancer-related deaths. Cases with residual disease did not differ between the two groups. Occurrence of second primary cancer was also similar between the two groups. Thus, the 14-day LOS program did not compromise oncological outcomes compared to patients without active management of LOS.

To minimize the potential bias from the bony and soft tissue reconstruction, we also conducted a subgroup analysis using the patients with radial forearm and anterolateral thigh flaps. Again, we found that there was no difference in terms of complications and oncological outcomes between the two groups (Supplementary Table 4). In these subgroups, there were more patients with anterolateral thigh flap in the group 1 , and more with radial free flaps in the group 2. In the group 1, patients with radial forearm flap had significantly shorter LOS, compared to LOS in patients with anterolateral thigh flap. However, in the group 2, the difference of LOS between anterolateral thigh and radial forearm flaps was minimal; suggesting that active management of LOS could shorten LOS further in patients with anterolateral thigh flaps. Probably, active management of LOS (such as early ambulation, early extubation or decannulation, swallowing rehabilitation) could enhance patient recovery or early discharge from hospital in patients even with bulky flaps. Similarly with thin radial forearm flap, active management of LOS can also reduce LOS significantly, compared to those without the program.

Regarding the medical expenses, group 1 patients without re-

Table 4. Comparison of two groups according to length of hospital stay

\begin{tabular}{|c|c|c|c|c|c|c|c|}
\hline \multirow{2}{*}{ Variable } & \multicolumn{2}{|c|}{ Length of hospital stay } & \multirow{2}{*}{$P$-value } & \multirow{2}{*}{ Variable } & \multicolumn{2}{|c|}{ Length of hospital stay } & \multirow{2}{*}{$P$-value } \\
\hline & $\leq 30$ Days $(n=135)$ & $>30$ Days $(n=33)$ & & & $\leq 30$ Days $(n=135)$ & $>30$ Days $(n=33)$ & \\
\hline Age (yr) & $56.39 \pm 1.1(23-86)$ & $58.6 \pm 2.1(29-86)$ & 0.477 & Flap & & & 0.016 \\
\hline $\begin{array}{l}\text { Sex } \\
\text { (male:female) }\end{array}$ & $95: 40(70.4: 29.6)$ & 22:11 (66.7:33.3) & 0.677 & $\begin{array}{l}\text { Anterolateral } \\
\text { thigh }\end{array}$ & $66(48.9)$ & $21(63.6)$ & \\
\hline \multirow{2}{*}{$\begin{array}{l}\text { Patient physical } \\
\text { status }\end{array}$} & & & \multirow[t]{2}{*}{0.802} & Radial forearm & $50(37.0)$ & $4(12.1)$ & \\
\hline & & & & Fibula & $8(5.9)$ & $2(6.1)$ & \\
\hline ASA 1 & $33(24.4)$ & $6(18.2)$ & & Scapula & $8(5.9)$ & $3(9.1)$ & \\
\hline ASA 2 & $93(68.9)$ & $25(75.8)$ & & Multi-flaps & 0 & $1(3.0)$ & \\
\hline ASA 3 & $9(6.6)$ & $2(6.1)$ & & Others & $3(2.2)$ & $2(6.1)$ & \\
\hline Primary site & & & 0.424 & \multirow{2}{*}{$\begin{array}{l}\text { Surgical } \\
\text { complication }\end{array}$} & \multirow[t]{2}{*}{$49(36.3)$} & \multirow[t]{2}{*}{$22(66.6)$} & \multirow[t]{4}{*}{0.002} \\
\hline \multirow{2}{*}{$\begin{array}{l}\text { Oral cavity \& } \\
\text { oropharynx }\end{array}$} & \multirow[t]{2}{*}{99 (73.3) } & \multirow[t]{2}{*}{$22(66.7)$} & & & & & \\
\hline & & & & \multirow{2}{*}{$\begin{array}{l}\text { Transposed } \\
\text { flap } \\
\text { complication }\end{array}$} & \multirow[t]{2}{*}{$18(13.3)$} & \multirow[t]{2}{*}{$13(39.3)$} & \\
\hline $\begin{array}{l}\text { Larynx \& } \\
\text { hypopharynx }\end{array}$ & $4(3.0)$ & $3(9.1)$ & & & & & \\
\hline \multirow{2}{*}{$\begin{array}{l}\text { Nasal cavity \& } \\
\text { paranasal } \\
\text { sinus }\end{array}$} & \multirow[t]{2}{*}{$14(10.4)$} & \multirow[t]{2}{*}{$5(15.2)$} & & $\begin{array}{c}\text { Flap fail \& } \\
\text { revision }\end{array}$ & 3 & 4 & \\
\hline & & & & \multirow{3}{*}{$\begin{array}{l}\text { Partial } \\
\text { necrosis \& } \\
\text { congestion }\end{array}$} & \multirow[t]{3}{*}{7} & \multirow[t]{3}{*}{8} & \\
\hline Salivary gland & $2(1.5)$ & 0 & & & & & \\
\hline Others & $16(11.9)$ & $3(9.1)$ & & & & & \\
\hline \multicolumn{4}{|l|}{ pTNM stage } & \multirow{2}{*}{$\begin{array}{l}\text { Flap } \\
\text { dehiscence }\end{array}$} & \multirow[t]{2}{*}{8} & 1 & \\
\hline T status & & & $<0.001$ & & & & \\
\hline T1 & 26 (19.3) & $1(3.0)$ & & Flap donor site & $7(5.1)$ & $1(3.0)$ & \\
\hline T2 & $57(42.2)$ & $7(21.2)$ & & complications & & & \\
\hline T3 & $20(14.8)$ & $4(12.1)$ & & Neck wound & $14(10.3)$ & $7(21.2)$ & \\
\hline $\mathrm{T} 4 \mathrm{a}$ & $27(20.0)$ & $20(60.6)$ & & problems & & & \\
\hline $\mathrm{T} 4 \mathrm{~b}$ & $4(3.0)$ & $1(3.0)$ & & Fistula & $2(1.4)$ & $1(3.0)$ & \\
\hline $\mathrm{T} 4 \mathrm{C}$ & $1(0.7)$ & 0 & & Others & $8(5.9)$ & 0 & \\
\hline N status & & & 0.846 & Medical & $10(7.1)$ & $6(18.1)$ & 0.067 \\
\hline NO & $79(58.5)$ & $18(54.5)$ & & Cardiac & $4(3.0)$ & 0 & \\
\hline N1 & $16(11.9)$ & 4 (12.1) & & Respiratory & $1(0.7)$ & $2(6.0)$ & \\
\hline $\mathrm{N} 2 \mathrm{a}$ & $5(3.7)$ & 0 & & Neurological & $3(2.2)$ & $\begin{array}{l}2(b .0) \\
2(6.0)\end{array}$ & \\
\hline $\mathrm{N} 2 \mathrm{~b}$ & 26 (19.3) & 9 (27.3) & & Psvchiatric & $1(0.7)$ & $\begin{array}{l}2(0.0) \\
1(3.0)\end{array}$ & \\
\hline N2c & $8(5.9)$ & $2(6.1)$ & & Psycnlatric & $\begin{array}{c}1(0.7) \\
0\end{array}$ & $1(3.0)$ & \\
\hline N3 & $1(0.7)$ & 0 & & Endecrine & $1(0.7)$ & $\begin{array}{c}1(3.0) \\
0\end{array}$ & \\
\hline M status & & & 0.625 & $\begin{array}{l}\text { Endocrine } \\
\text { Enrollment of a }\end{array}$ & $\begin{array}{c}1(0.7) \\
41(30.4)\end{array}$ & $2(6.1)$ & 0.003 \\
\hline MO & 133 (98.5) & $33(100)$ & & 14-day LOS & $4.7(00.4)$ & & \\
\hline M1 & $2(1.5)$ & 0 & & program & & & \\
\hline
\end{tabular}

Values are presented as median \pm standard deviation (range) or number (\%).

ASA, American Society of Anesthesiologists Physical Status Classification; pTNM, pathological TNM; LOS, length of in-hospital stay. 
Table 5. Logistic regression analyses predicting longer hospital stay (>30 days)

\begin{tabular}{|c|c|c|c|c|}
\hline \multirow{2}{*}{ Variable } & \multicolumn{2}{|c|}{ Univariate analysis } & \multicolumn{2}{|c|}{ Multivariate analysis } \\
\hline & $\mathrm{OR}(95 \% \mathrm{Cl})$ & $P$-value & $\mathrm{OR}(95 \% \mathrm{Cl})$ & $P$-value \\
\hline Age (continuous) & $1.014(0.984-1.046)$ & 0.362 & & \\
\hline Sex (male/female) & $1.187(0.527-2.676)$ & 0.679 & & \\
\hline ASA physical status $(3 / 2 / 1)$ & & 0.560 & & \\
\hline Primary site (oral cavity \& oropharynx/others) & $1.001(0.756-1.325)$ & 0.994 & & \\
\hline Pathology (SCC/others) & $0.980(0.946-1.015)$ & 0.255 & & \\
\hline T status (T3-4/T1-2) & $4.988(2.093-11.886)$ & $<0.001$ & $4.435(1.735-11.337)$ & 0.002 \\
\hline N status (N2-3/N0-1) & $1.187(0.527-2.676)$ & 0.679 & & \\
\hline M status (M1/M0) & $\mathrm{NC}$ & 0.999 & & \\
\hline Reconstruction method (ALT/RF/others) & & 0.473 & & \\
\hline Surgical complication (yes/no) & $3.510(1.570-7.846)$ & 0.002 & $6.056(2.053-17.868)$ & 0.001 \\
\hline Medical complication (yes/no) & $2.778(0.930-8.297)$ & 0.067 & $5.530(1.306-23.412)$ & 0.020 \\
\hline Enrollment of a 14-day LOS program & $0.148(0.034-0.647)$ & 0.011 & $0.164(0.035-0.755)$ & 0.020 \\
\hline
\end{tabular}

OR, odds ratio; Cl, confidence interval; ASA, American Society of Anesthesiologists Physical Status Classification; SCC, squamous cell carcinomas; NC, not calculated; ALT, anterolateral thigh; RF, radial forearm; LOS, length of in-hospital stay.

ceiving active management of hospital stay paid 1.4 times more for their hospital stays, compared to group 2 patients (odds ratio [OR], 1.39; 95\% CI, 1.46 to 1.31) (Supplementary Table 5). Thus, a 14-day LOS program could lower medical cost for HNC patients undergoing HNC surgery and free flap reconstruction, particularly for patients under the national medical insurance coverage.

In our series, the average stay of intensive care unit (ICU) was 1.61 days (standard deviation, 1.09) with a range of 1 to 9 days. The number of patients with prolonged ICU stay (3 days and more) was $17(10.1 \%)$. There was no statistical difference in the number of patients with long ICU stay between the two groups; 15 in the group 1 vs. 2 in the group $2(P=0.243)$.

\section{Risk factors for long hospital stay ( $>30$ days)}

A total of 168 patients were subdivided into two groups according to 30-day LOS: 135 patients with LOS $\leq 30$ days and 33 patients with LOS $>30$ days (Table 4). Comparison between the two groups showed no significant difference in age, sex, patient physical status, primary site, $\mathrm{N}$ or M status. In the shorter LOS group, $\mathrm{T} 1$ and $\mathrm{T} 2$ stages were predominant $(19.3 \%$ and $42.2 \%$, respectively). Meanwhile, $60.6 \%$ of patients in the longer LOS group had T4a stage. Anterolateral thigh free flap was the most frequent reconstruction type for the defect in the longer LOS group, reflecting a need for large volume reconstruction and more advanced T stage in the longer LOS group $(P=0.016)$.

In terms of postoperative complication, surgery-related complication rate was $36.3 \%$ in the shorter LOS group and $66.6 \%$ in the longer LOS group $(P=0.002)$. Transposed flap complications, neck wound problems, and fistula complications were more frequently observed in the longer LOS group. Medical complications were also more prevalent in the longer LOS group than those in the shorter LOS group, although the difference was not statistically significant $(P=0.067)$. Interestingly, the longer LOS group had less patients who had been enrolled into the 14-day LOS program $(P=0.003)$.

Results of univariate and multivariate logistic regression analyses of variables predictive of long LOS ( $>30$ days) are shown in Table 5. Variables found to independently predict long LOS were high T status (T3-T4/T1-2: OR, 4.435; 95\% CI, 1.735 to 11.337; $P=0.002$ ), occurrence of surgical complications (OR, 6.056; $95 \%$ CI, 2.053 to $17.868 ; P=0.001)$ and medical complications (OR, 5.530; 95\% CI, 1.306 to 23.412; $P=0.020$ ). In accordance with previous results, the enrollment of a 14-day LOS program had less LOS ( $\leq 30$ days; OR, $0.164 ; 95 \% \mathrm{CI}, 0.035$ to $0.755 ; P=0.020)$. In summary, initial high $\mathrm{T}$ status (T3-4) and occurrence of postoperative complications (surgical or medical) were independent risk factors for longer hospital stay ( $>30$ days).

\section{DISCUSSION}

HNC resection with free flap reconstruction entails complex surgical techniques, in which several host and treatment parameters could be associated with surgical and medical complications and prolonged LOS [20]. These parameters include long duration of surgery, inconsistent postoperative recovery, and poor general medical status of HNC patients $[7,8,13,17,20]$. In spite of these pitfalls, on-site reconstruction of large HNC defect has become a standard method for HNC surgery, because it could provide better functional outcome with enhanced wound healing and rapid patient recovery $[5,10]$.

From the viewpoint of medical resource distribution, HNC surgery with free flap reconstruction has been considered a costinefficient treatment method because of large requirement of resources [1]. However, surgical refinements and improved postoperative care have turned this complex surgery to standardized modality with less surgical morbidity and LOS [1,7].

LOS is regarded as an important parameter of resource utili- 
zation and costs [7]. Unfortunately, most previous studies have focused on predictors of complication and prolonged LOS, and there have been only a few reports about LOS in HNC cancer and free flap reconstruction $[7,8,17]$. Thus, there is still no consensus in appropriate duration of in-patient hospital care for these patients.

In this study, we tried a 14-day LOS program for HNC patients with free flap reconstruction. First, before common application of the program, we investigated the safety because shorter hospital stay may have potential risk of late complication and readmission. Our results revealed that patients under our 14day LOS program had comparable oncological outcomes and surgical/medical complications in spite of shorter LOS. In financial perspective, medical cost in the group under a 14-day LOS program was significantly reduced compared to that in the control group. This could be extrapolated to resource redistribution in a scale of national health insurance system.

Detailed preoperative assessment, active wound management, early rehabilitation, and positive psychological encouragement were essential components of our 14-day LOS program. In the control group, the first three components of our 14-day LOS program were also routinely employed to the patients. However, psychological encouragement and feedback were provided to patients under a 14-day LOS program, ensuring that the patient had been recovering well. In addition, the patient was noticed frequently of the time point of hospital discharge, so that the patient could be ready for it in advance.

Recently, several programs have been launched to improve patient recovery with many fields of surgery. ERAS, enhanced recovery program (ERP) and fast-track programs are multidisciplinary approach to accelerate recovery, reduce morbidity and shorten LOS in many surgical specialties [19,21-26]. In head and neck surgery, there have been some reports about these programs, with promising results $[17,27,28]$. The mean LOS under ERAS for HNC patients was 14.55 days, similar to our results [17]. It could be further reduced to 10 days in patients having free tissue transfer for HNC [27].

In terms of key components in ERAS (or ERP) program and our 14-day LOS program, these programs included multidisciplinary care, intensive intraoperative anesthetic management, adequate pain control, nutritional support, early rehabilitation, and psychological counseling and encouragement $[17,25,27]$. However, in our study, patients in the control group also received the similar multidisciplinary postoperative care as patients under 14-day LOS program. Thus, the most important aspect for successful implementation of this program seems to aware and understand the necessity of the program for both responsible physicians and patients.

Even with similar findings of our study to previous reports, our study showed some unique results. First, we demonstrated that a 14-day LOS program did not compromise oncological outcomes. This has never been investigated thoroughly in pa- tients with HNC surgery and free flap reconstruction previously [27]. Particularly in South Korea, where people are enrolled into the national health insurance system, this is the first report about LOS for HNC patients. These patients tend to stay longer in hospitals because of low individual medical cost. Our results could provide groundwork for resource redistribution in public healthcare system, even in major and complex HNC surgery.

Secondary outcome of this study was to identify patients and treatment variables that would allow us to stratify a patient's prolonged LOS. In our results, initial high T status (T3-4) and occurrence of postoperative surgical or medical complications were important risk factors predictive of LOS $>30$ days. Reciprocally, a 14-day LOS program can be more suitable for patients with T1-2 tumors regardless of $\mathrm{N}$ status and without postoperative complications. To achieve both optimal surgical outcomes and shorter LOS safely, meticulous managements are required for high risk patients (advanced T stage) using careful preoperative planning, prevention of overall complication, and intensive postoperative monitoring.

Lastly, this study has some limitations. In our analyses, we excluded patients with initial nonsurgical treatments and salvage surgery, because the extent and modalities of nonsurgical treatment could significantly prolong postoperative care and LOS ( $n=19$, LOS 30-220 days in our series). Thus, our conclusion may be only valid in patients with previously untreated HNC.

Another thing to note was that shorter LOS in the group 2 may result from more frequent use of anterolateral thigh flap in the group 1 (more radial forearm flap in the group 2) (Table 1 , Supplementary Table 4). However, longer hospital stay ( $>30$ days) did not depend on the reconstruction flap types (Table 5) and LOS in patients with anterolateral thigh free flap in the group 2 was only 14.5 days (Supplementary Table 4). Thus, it is reasonable to think that the shorter LOS in the group 2 can be an outcome from the active management of LOS.

In addition, there might be potential selection bias from this retrospective study. Although one surgeon responsible for a 14day LOS program and other two surgeons without this program had similar clinical experiences, individual preferences and selection criteria, and surgical indications might differ in treatment decisions of their patients. This point requires further validation through a prospective randomized study.

Nevertheless, our results suggest that a 14-day LOS program could be safe and feasible in HNC patients with complex surgery, such as free flap reconstruction. To achieve this goal, careful management for T3-4 tumors and prevention of postoperative complications seem to be necessary.

\section{CONFLICT OF INTEREST}

No potential conflict of interest relevant to this article was reported. 


\section{ACKNOWLEDGMENTS}

This work was supported by a grant (No. 2015R1D1A1A09056771) of the National Research Foundation of Korea funded by the Ministry of Education, Science and Technology, Korea and a 2016 basic-clinical collaborative research grant (SMX1161461) of Samsung Biomedical Research Institute (SBRI), Seoul, Republic of Korea.

\section{ORCID}

$\begin{array}{ll}\text { Ji-Eun Choi } & \text { https://orcid.org/0000-0001-6887-8627 } \\ \text { Han-Sin Jeong } & \text { https://orcid.org/0000-0003-4652-0573 }\end{array}$

\section{AUTHOR CONTRIBUTIONS}

Conceptualization: JEC, HSJ. Data curation: HK, SYC, JP, MKC, CHB. Formal analysis: JEC, SYC, JP. Funding acquisition: HSJ. Methodology: MKC, CHB, HSJ. Project administration: HSJ. Visualization \& Writing - original draft: JEC, HSJ.Writing - review \& editing: all authors.

\section{SUPPLEMENTARY MATERIALS}

Supplementary materials can be found via https://doi.org/10. 21053/ceo.2018.01235.

\section{REFERENCES}

1. Rosenthal E, Carroll W, Dobbs M, Scott Magnuson J, Wax M, Peters G. Simplifying head and neck microvascular reconstruction. Head Neck. 2004 Nov;26(11):930-6.

2. Cordeiro PG, Hidalgo DA. Soft tissue coverage of mandibular reconstruction plates. Head Neck. 1994 Mar-Apr;16(2):112-5.

3. Kroll SS, Reece GP, Miller MJ, Schusterman MA. Comparison of the rectus abdominis free flap with the pectoralis major myocutaneous flap for reconstructions in the head and neck. Am J Surg. 1992 Dec; 164(6):615-8.

4. Schusterman MA, Kroll SS, Weber RS, Byers RM, Guillamondegui O, Goepfert $\mathrm{H}$. Intraoral soft tissue reconstruction after cancer ablation: a comparison of the pectoralis major flap and the free radial forearm flap.Am J Surg. 1991 Oct;162(4):397-9.

5. Stern JR, Keller AJ,Wenig BL. Evaluation of reconstructive techniques of oropharyngeal defects. Ann Plast Surg. 1989 Apr;22(4):332-6.

6. Kroll SS, Evans GR, Goldberg D, Wang BG, Reece GP, Miller MJ, et al. A comparison of resource costs for head and neck reconstruction with free and pectoralis major flaps. Plast Reconstr Surg. 1997 Apr; 99(5):1282-6.

7. Ryan MW, Hochman M. Length of stay after free flap reconstruction of the head and neck. Laryngoscope. 2000 Feb;110(2 Pt 1):210-6.

8. Girod A, Brancati A, Mosseri V, Kriegel I, Jouffroy T, Rodriguez J. Study of the length of hospital stay for free flap reconstruction of oral and pharyngeal cancer in the context of the new French casemix-based funding. Oral Oncol. 2010 Mar;46(3):190-4.

9. Cohen J, Stock M, Chan B, Meininger M,Wax M, Andersen P, et al. Microvascular reconstruction and tracheotomy are significant determinants of resource utilization in head and neck surgery. Arch Otolaryngol Head Neck Surg. 2000 Aug;126(8):947-9.

10. Haughey BH, Wilson E, Kluwe L, Piccirillo J, Fredrickson J, Sessions $\mathrm{D}$, et al. Free flap reconstruction of the head and neck: analysis of 241 cases. Otolaryngol Head Neck Surg. 2001 Jul;125(1):10-7.

11. Kiener JL, Hoffman WY, Mathes SJ. Influence of radiotherapy on microvascular reconstruction in the head and neck region. Am J Surg. 1991 Oct;162(4):404-7.

12. Lueg EA. Comparing microvascular outcomes at a large integrated health maintenance organization with flagship centers in the United States. Arch Otolaryngol Head Neck Surg. 2004 Jun;130(6):779-85.

13. Cloke DJ, Green JE, Khan AL, Hodgkinson PD, McLean NR. Factors influencing the development of wound infection following free-flap reconstruction for intra-oral cancer. Br J Plast Surg. 2004 Sep;57(6): 556-60.

14. Klug C, Berzaczy D, Reinbacher H, Voracek M, Rath T, Millesi W, et al. Influence of previous radiotherapy on free tissue transfer in the head and neck region: evaluation of 455 cases. Laryngoscope. 2006 Jul;116(7):1162-7.

15. Papi M, Pontecorvi L, Setola R. A new model for the length of stay of hospital patients. Health Care Manag Sci. 2016 Mar;19(1):58-65.

16. Bonde C, Khorasani H, Eriksen K, Wolthers M, Kehlet H, Elberg J. Introducing the fast track surgery principles can reduce length of stay after autologous breast reconstruction using free flaps: a case control study. J Plast Surg Hand Surg. 2015;49(6):367-71.

17. Coyle MJ, Main B, Hughes C, Craven R, Alexander R, Porter G, et al. Enhanced recovery after surgery (ERAS) for head and neck oncology patients. Clin Otolaryngol. 2016 Apr;41(2):118-26.

18. Willemsen PJ,Appeltans BM. Hospital stay of 2 days after open sigmoidectomy with a multimodal rehabilitation programme. Br J Surg. 1999 Jul;86(7):968-9.

19. Nicholson A, Lowe MC, Parker J, Lewis SR, Alderson P, Smith AF. Systematic review and meta-analysis of enhanced recovery programmes in surgical patients. Br J Surg. 2014 Feb;101(3):172-88.

20. Patel RS, McCluskey SA, Goldstein DP, Minkovich L, Irish JC, Brown $\mathrm{DH}$, et al. Clinicopathologic and therapeutic risk factors for perioperative complications and prolonged hospital stay in free flap reconstruction of the head and neck. Head Neck. 2010 Oct;32(10):134553.

21. Lohsiriwat V. Enhanced recovery after surgery vs conventional care in emergency colorectal surgery. World J Gastroenterol. 2014 Oct; 20(38):13950-5.

22. Pearsall EA, Meghji Z, Pitzul KB, Aarts MA, McKenzie M, McLeod RS, et al.A qualitative study to understand the barriers and enablers in implementing an enhanced recovery after surgery program. Ann Surg. 2015 Jan;261(1):92-6.

23. Xu X, Wang Y, Feng T, Zhao X, Liao Y, JiW, et al. Nonstrict and individual enhanced recovery after surgery (ERAS) in partial hepatectomy. Springerplus. 2016 Nov;5(1):2011.

24. Ding J, Sun B, Song P, Liu S, Chen H, Feng M, et al. The application of enhanced recovery after surgery (ERAS)/fast-track surgery in gastrectomy for gastric cancer: a systematic review and meta-analysis. Oncotarget. 2017 Jun;8(43):75699-711.

25. Schmidt CR. Enhanced recovery after surgery-Summary recommendations. J Surg Oncol. 2017 Oct;116(5):638.

26. Zhao Y, Qin H,WuY, Xiang B. Enhanced recovery after surgery program reduces length of hospital stay and complications in liver resection: a PRISMA-compliant systematic review and meta-analysis of randomized controlled trials. Medicine (Baltimore). 2017 Aug; 96(31):e7628. 
27. Bater M, King W, Teare J, D'Souza J. Enhanced recovery in patients having free tissue transfer for head and neck cancer: does it make a difference? Br J Oral Maxillofac Surg. 2017 Dec;55(10):1024-9.

28. Gemma M, Toma S, Lira Luce F, Beretta L, Braga M, Bussi M. En- hanced recovery program (ERP) in major laryngeal surgery: building a protocol and testing its feasibility. Acta Otorhinolaryngol Ital. 2017 Dec;37(6):475-8. 